\title{
Las mil caras de la piel en enfermos con enfermedad COVID-19
}

\author{
The thousand faces of skin in patients \\ with COVID-19 disease
}

\author{
María Graciela Guzmán Perera, * Jorge Flores Ochoa, ${ }^{\ddagger}$ \\ Mariana Itzel López Garza ${ }^{\S}$
}

Citar como: Guzmán PMG, Flores OJ, López GMI. Las mil caras de la piel en enfermos con enfermedad COVID-19. Acta Med Grupo Angeles. 2021; 19 (s1): s9-s20. https://dx.doi.org/10.35366/101023

\section{Resumen}

Se desconoce la frecuencia real de las manifestaciones cutáneas asociadas con la infección por SARS-CoV-2. Aun con técnicas avanzadas de inmunohistoquímica con proteínas virales, el hallazgo del virus en la piel es controvertido, por ello se consideran lesiones paravirales. La fisiopatología de estos daños por COVID-19 es compleja y su morfología heterogénea. Los mecanismos citotóxicos del SARS-CoV-2 parecen causar estimulación de los mastocitos, daño endotelial, dilatación vascular, infiltración perivascular y periglandular por linfocitos y neutrófilos, daño de interfaz y en ocasiones necrosis epidérmica focal. Los mecanismos de defensa contra la infección parecen contribuir a la génesis de las lesiones reportadas, así como la toxicidad directa del virus, la activación humoral y celular inmediata y tardía, las respuestas inmunes; la tormenta de citoquinas con microtrombosis y la probable activación de otros virus (herpes 6-7). El uso de múltiples fármacos puede desempeñar un papel importante. Desde el punto de vista clínico, los pacientes presentan un amplio espectro de combinaciones de lesiones elementales. Aun cuando en informes de series europeas se reporta una alta incidencia de lesiones inflamatorias acrales. En México las erupciones maculopapulares son las manifestaciones más frecuentes. Existe una gran cantidad de diagnósticos diferenciales, infecciones virales, bacterianas, parasitarias y cuadros clínicos reaccionales, los cuales deben seguir siendo considerados.

Palabras clave: Paraviral, exantema, vesículas, pápulas, ronchas, citotoxicidad.
Abstract

The actual frequency of skin manifestations associated with SARS-CoV-2 infection is unknown. Even with advanced immunohistochemical techniques with viral proteins, the finding of the virus in the skin is still controversial, therefore, it is considered that the lesions are paraviral. The pathophysiology of COVID-19 skin lesions is complex and their morphology is heterogeneous. Cytotoxic mechanisms of SARS-CoV-2 appear to cause mast cell stimulation, endothelial damage, vascular dilation, perivascular and periglandular infiltration by lymphocytes and neutrophils, interface damage, and occasionally focal epidermal necrosis. The host defense mechanisms against infection seem to contribute to the genesis of lesions reported in the literature. Also, the direct toxicity of SARS-CoV-2; activation of immediate, late, humoral and cellular immune responses; cytokine storm with micro-thrombosis; as well as the probable activation of other viruses (herpes 6-7) and the use of multiple drugs can play an important role. From a clinical point of view, patients present a wide spectrum of combinations of elementary lesions. European series report a high incidence of acral inflammatory lesions. In Mexico, maculopapular rashes are the most frequent manifestations. There are a large number of differential diagnosis, viral, bacterial, parasitic infections and reactional clinical pictures, must continue to take into account.

Keywords: Paraviral, exanthema, vesicles, papules, hives, cytotoxicity.
* Médico Dermatólogo del Hospital Ángeles Pedregal, expresidenta de la Academia Mexicana de Dermatología, Fundación Mexicana para la Dermatología y del Colmexiderma. México.

* Médico General. Medicina privada. México.

§ Médico residente de Pediatría del Hospital Ángeles Pedregal. México.

\section{Correspondencia:}

María Graciela Guzmán Perera

Correo electrónico: graceguzman07@gmail.com

www.medigraphic.com/actamedica 


\section{INTRODUCCIÓN}

Las enfermedades infecciosas de diversa índole (viral, bacteriana, parasitaria, etc.) son capaces de causar manifestaciones en la piel, típicas o atípicas. ${ }^{1-5}$ Las patologías inflamatorias sistémicas, autoinmunes y reaccionales podrían así mismo causar cuadros clínicos cutáneos que complican el diagnóstico. ${ }^{1-3}$

Es posible diferenciarlas conociendo profundamente la combinación de erosiones elementales, como eritema, máculas eritematosas o purpúricas, en placas o en red, pápulas, vesículas, pústulas, habones, costras, etc. Así como los síntomas que las acompañan (Tabla 1). ${ }^{2}$

No en todos los padecimientos virales los detrimentos cutáneos son producidos en forma directa por el virus. En el caso de virus de DNA como el varicela-zóster, es claro que así es, ya que sus inclusiones se pueden aislar de las lesiones, tanto en la varicela como en el herpes zóster. Otras enfermedades virales causan exantemas de diversa morfología, aunque pudieran ser muy característicos, como en el caso de la afección guante-calcetín (común en parvovirus B 27), no se ha encontrado el virus en las heridas, pudiendo presentarse cuadros similares causados por gérmenes distintos. Por ello se les denomina paravirales, pudiendo ser también parabacterianas o reaccionales (Tablas 1 y 2). ${ }^{1-8}$ Las principales diferencias se encuentran en las Tablas 2 a 5 . El SARS-CoV-2 es capaz de imitar cualquier cuadro clínico.

\section{FISIOPATOLOGÍA DE LAS LESIONES CUTÁNEAS POR SARS-CoV-2}

La aparición de lesiones en la piel, en el caso del SARSCoV-2, es compleja, implica efectos citotóxicos causados por el germen, activando los receptores para enzima convertidora de angiotensina 2 (ACE2) y las proteínas transportadoras transmembrana (TMPRSS2), éstas permiten la entrada del virus y su primera replicación. Después de la primera viremia, éstos se fijan al endotelio vascular, ya que expresan grandes cantidades de ACE2. Ahí ocurre una segunda replicación.

Los fragmentos de la cápside entran en contacto con MHC-1, éstos activan los CD8 para iniciar un ataque a los tejidos que expresen ACE2 como los alveolos tipo $2 .{ }^{9}$ Las células dendríticas, monocitos y macrófagos elevan la producción de interferón, el cual estimula la intervención de la inmunidad innata. Los linfocitos se activan y empiezan a liberar gran cantidad de mediadores capaces de activar la inmunidad humoral tanto inmediata como tardía y celular del huésped. La sobrerregulación de estos eventos provoca una tormenta de citoquinas que favorece el daño endotelial de los vasos dérmicos, la migración de linfocitos y neutrófilos que dañan la unión dermoepidérmica. Finalmente, se presenta trombosis de la microcirculación causando severa isquemia de los tejidos, incluyendo la piel (Figura 1). ${ }^{10,11}$

El coronavirus SARS-CoV-2 vino a retar la habilidad diagnóstica de los médicos. Hasta el momento ha mostrado su capacidad para provocar cualquier cuadro clínico de los antes mencionados. Su semiología es diversa y heterogénea, lo cual complica su diagnóstico diferencial. ${ }^{11} \mathrm{La}$ presencia del virus en las lesiones de la piel aún es una controversia. ${ }^{12-17}$

Cuando inició la pandemia en Wuhan, las primeras descripciones del proceso no incluyeron las manifestaciones cutáneas, se les consideró un problema secundario. Semanas más tarde, se observó un exantema purpúrico similar al dengue en Tailandia. ${ }^{18}$

En el norte de Italia, Recalcati ${ }^{19}$ fue el primero que describió que el 20\% de un grupo de 88 enfermos hospitalizados con enfermedad activa, habían presentado diversas manifestaciones dermatológicas, polimorfas, desde urticaria, exantemas de diverso tipo a lesiones necróticas.

Las condiciones de aislamiento de los infectados dificultaba su documentación fotográfica y su estudio histológico.

Las consultas por telemedicina y por otros medios electrónicos han hecho pensar que la frecuencia de brotes cutáneos es más alta, sin embargo, en realidad se desconoce la incidencia de la afección de la piel por este virus; la serie más grande publicada a la fecha es de 996 casos, no parece ser un virus dermatotrópico. ${ }^{20}$

\section{LESIONES CUTÁNEAS POR SARS-CoV-2}

La primera gran serie fue publicada por la doctora GalvánCasas y colaboradores, ${ }^{21}$ quienes lograron reunir 375 casos en España y clasificaron las lesiones en cinco grupos:

1. Seudosabañones: pápulas eritematoedematosas con algunas vesículo-pústulas en áreas acrales, afectando los dedos de manos y pies (seudosabañones o dedos COVID). Éstas habitualmente son simétricas. Afectan sobre todo a la población pediátrica y adultos jóvenes.

2. Exantema vesicular: aparición de vesículas pequeñas y medianas, con costras, más frecuente en el tórax y extremidades.

3. Urticaria con o sin angioedema: ronchas que inician en tronco y se diseminan a las extremidades, algunos eventos asociados a angioedema.

4. Exantema maculopapular: se inicia habitualmente en el tórax y se disemina en forma irregular a las extremidades y dorso de las manos. Tiene distribución perifolicular, presenta escamas. Las lesiones pueden confluir y adquieren en algunos casos morfología "en blanco de tiro".

5. Eritemas livedoides y retiformes, cianosis acral: sugieren vasculopatía oclusiva e isquemia. 
Tabla 1: Manifestaciones cutáneas de infecciones virales comparadas con COVID-19.

\begin{tabular}{|c|c|c|c|c|c|c|c|c|}
\hline Virus & Eritema & Urticaria & $\begin{array}{l}\text { Exantema } \\
\text { morbiliforme }\end{array}$ & $\begin{array}{l}\text { Exantema } \\
\text { vesicular }\end{array}$ & $\begin{array}{c}\text { Exantema } \\
\text { maculopapular }\end{array}$ & $\begin{array}{l}\text { Exantema } \\
\text { purpúrico o } \\
\text { isquemia }\end{array}$ & $\begin{array}{l}\text { Enantema } \\
\text { Afección } \\
\text { Mucosas }\end{array}$ & Otros \\
\hline $\begin{array}{l}\text { Sarampión (virus del } \\
\text { sarampión) }\end{array}$ & & & Sí & & $\begin{array}{c}\text { Inicio } \\
\text { retroauricular, } \\
\text { diseminación } \\
\text { cefalocaudal }\end{array}$ & & Manchas de Koplik & $\begin{array}{l}\text { Conjuntivitis } \\
\text { Descamación }\end{array}$ \\
\hline $\begin{array}{l}\text { Rubéola (virus de la } \\
\text { rubéola) }\end{array}$ & & & Sí & & $\begin{array}{l}\text { Progresión rápida } \\
\text { Cefalocaudal }\end{array}$ & & $\begin{array}{l}\text { Manchas de } \\
\text { Forchheimer (pete- } \\
\text { quias en paladar) }\end{array}$ & $\begin{array}{l}\text { Descamación } \\
\text { Adenopatía } \\
\text { Retroauricular }\end{array}$ \\
\hline $\begin{array}{l}\text { Varicela (virus de } \\
\text { varicela zóster) }\end{array}$ & & & & $\begin{array}{l}\text { Vesículas con } \\
\text { contenido } \\
\text { seroso claro, } \\
\text { diferentes estados } \\
\text { evolutivos. Con } \\
\text { prurito }\end{array}$ & $\begin{array}{c}\text { Al comienzo en } \\
\text { piel cabelluda y } \\
\text { cara. Se extienden } \\
\text { a tronco y } \\
\text { extremidades }\end{array}$ & & & \\
\hline $\begin{array}{l}\text { Coxsackie } \\
\text { (Coxsackie virus) }\end{array}$ & & & & Manos, pies y & y extremidades & Petequias & Fiebre aftosa & \\
\hline Enterovirus & & & Sí & & $\begin{array}{l}\text { Pequeñas pápulas } \\
\text { rojas con halo } \\
\text { pálido en mejillas y } \\
\text { extremidades }\end{array}$ & & Estomatitis erosiva & \\
\hline $\begin{array}{l}\text { Quinta enfermedad/ } \\
\text { eritema infeccioso } \\
\text { (parvovirus B19) }\end{array}$ & $\begin{array}{l}\text { En mejillas, signo } \\
\text { de la bofetada, } \\
\text { respeta puente } \\
\text { nasal y área } \\
\text { perioral }\end{array}$ & & & & $\begin{array}{l}\text { Elevado, seguido } \\
\text { de patrón en } \\
\text { encaje, o reticular } \\
\text { (segunda fase) }\end{array}$ & $\begin{array}{l}\text { En guante y } \\
\text { calcetín }\end{array}$ & & \\
\hline Hepatitis B/C & Sí & $\begin{array}{l}\text { Formas } \\
\text { crónicas }\end{array}$ & & & $\begin{array}{l}\text { En tronco y } \\
\text { extremidades que } \\
\text { resuelve cuando } \\
\text { inicia la ictericia }\end{array}$ & & & $\begin{array}{c}\text { Eritema nudoso } \\
\text { Eritema } \\
\text { multiforme }\end{array}$ \\
\hline $\begin{array}{l}\text { Herpes simple } \\
\text { (HSV-1 y HSV-2) }\end{array}$ & & & & $\begin{array}{c}\text { Primoinfección } \\
\text { con vesículas con } \\
\text { base eritematosa, } \\
\text { dolorosas y a } \\
\text { veces umbilicadas, } \\
\text { diseminadas } \\
\text { Orolabial o genital }\end{array}$ & & & $\begin{array}{c}\text { Inicia con } \\
\text { gingivoestomatitis } \\
\text { en niños } \\
\text { Faringitis en el } \\
\text { adulto }\end{array}$ & Eritema polimorfo \\
\hline $\begin{array}{l}\text { Roséola exantema } \\
\text { súbito (HSV-6 y } \\
\text { HSV-7) }\end{array}$ & & & & & $\begin{array}{l}\text { Rosado-rojo, } \\
\text { en tronco y } \\
\text { cuello y raíz de } \\
\text { extremidades }\end{array}$ & & $\begin{array}{l}\text { Pápulas rojas en } \\
\text { paladar rojas y } \\
\text { úvula (manchas de } \\
\text { Nagayama) }\end{array}$ & Pitiriasis rosada \\
\hline $\begin{array}{l}\text { Mononucleosis } \\
\text { (VEB) }\end{array}$ & Multiforme & Sí & Sí & & $\begin{array}{l}\text { Tronco y } \\
\text { extremidades } \\
\text { proximales }\end{array}$ & Sí & $\begin{array}{c}\text { Faringitis } \\
\text { Petequias en unión } \\
\text { de paladar duro con } \\
\text { blando }\end{array}$ & $\begin{array}{c}\text { Fiebre y } \\
\text { adenopatías } \\
\text { Asociación a uso } \\
\text { de antibióticos }\end{array}$ \\
\hline $\begin{array}{l}\text { Citomegalovirus } \\
\text { (CMV) }\end{array}$ & & Sí & Sí & & Sí & Sí & & $\begin{array}{l}\text { Relacionado } \\
\text { con uso de } \\
\text { antibióticos } \\
\text { (ampicilina) }\end{array}$ \\
\hline Dengue & Facial inicial & & & & $\begin{array}{l}\text { Generalizado. } \\
\text { Islas blancas en } \\
\text { mar rojo }\end{array}$ & $\begin{array}{l}\text { Petequias, } \\
\text { púrpura, } \\
\text { equimosis }\end{array}$ & & \\
\hline Chikungunya & & & & & $\begin{array}{l}\text { Generalizado, } \\
\text { afecta palmas, } \\
\text { plantas y rostro }\end{array}$ & & & $\begin{array}{l}\text { Conjuntivitis } \\
\text { Úlceras en } \\
\text { mucosas }\end{array}$ \\
\hline Zika & & & & & $\begin{array}{l}\text { Diseminado en } \\
\text { tronco. Pruriginoso }\end{array}$ & Petequias & & Conjuntivitis \\
\hline $\begin{array}{l}\text { Enfermedad de } \\
\text { Kawasaki }\end{array}$ & $\begin{array}{l}\text { Pies y manos } \\
\text { Edema y } \\
\text { descamación }\end{array}$ & & & & $\begin{array}{l}\text { Lesiones en } \\
\text { blanco de tiro } \\
\text { eritema polimorfo }\end{array}$ & & $\begin{array}{c}\text { Conjuntivitis } \\
\text { Lengua } \\
\text { aframbuesada, } \\
\text { fisuras labiales }\end{array}$ & $\begin{array}{l}\text { Se desconoce } \\
\text { el virus } \\
\text { Afección cardiaca } \\
\text { Adenopatía } \\
\text { cervical }\end{array}$ \\
\hline COVID-19 & Palmas y plantas & Sí & Sí & Sí & Sí & Sí & Rara & $\begin{array}{l}\text { Seudosaba- } \\
\text { ñones }\end{array}$ \\
\hline
\end{tabular}


Tabla 2: Comparación de exantemas bacterianos y COVID-19.

\begin{tabular}{|c|c|c|c|c|c|c|c|c|}
\hline Bacterias & Eritema & Urticaria & $\begin{array}{c}\text { Exantema } \\
\text { morbiliforme y } \\
\text { descamativo }\end{array}$ & $\begin{array}{c}\text { Exantema } \\
\text { vesicular o } \\
\text { ampollas }\end{array}$ & $\begin{array}{c}\text { Exantema } \\
\text { maculopapular }\end{array}$ & $\begin{array}{l}\text { Exantema } \\
\text { purpúrico o } \\
\text { isquemia }\end{array}$ & $\begin{array}{l}\text { Enantema } \\
\text { Afección } \\
\text { Mucosas }\end{array}$ & Otros \\
\hline $\begin{array}{l}\text { Escarlatina (S. } \\
\text { pyogenes del } \\
\text { grupo A) }\end{array}$ & & & & & $\begin{array}{l}\text { Diseminado. } \\
\text { Respeta fosa } \\
\text { del codo y } \\
\text { triángulo } \\
\text { nasogeniano }\end{array}$ & $\begin{array}{l}\text { Líneas de } \\
\text { Pastia }\end{array}$ & $\begin{array}{l}\text { Lengua } \\
\text { de fresa. } \\
\text { Petequias } \\
\text { palatinas }\end{array}$ & $\begin{array}{l}\text { Descamación } \\
\text { sensación } \\
\text { de piel de } \\
\text { "gallina" }\end{array}$ \\
\hline $\begin{array}{l}\text { Síndrome de la } \\
\text { piel escaldada } \\
\text { (exotoxinas de S. } \\
\text { aureus) }\end{array}$ & $\begin{array}{l}\text { Generalizado } \\
\text { al inicio. } \\
\text { En cabeza } \\
\text { y posterior } \\
\text { cuerpo }\end{array}$ & & & $\begin{array}{l}\text { Ampollas } \\
\text { flácidas y } \\
\text { denudación } \\
\text { Nikolsky + }\end{array}$ & & & $\begin{array}{c}\text { Costras } \\
\text { y fisuras } \\
\text { periorales }\end{array}$ & Edema facial \\
\hline $\begin{array}{l}\text { Choque tóxico por } \\
\text { estafilococo ( } S \text {. } \\
\text { aureus) }\end{array}$ & Palmoplantar & & $\begin{array}{l}\text { Inicia en } \\
\text { el tronco, } \\
\text { centrípeta }\end{array}$ & & & & $\begin{array}{c}\text { Eritema } \\
\text { y lengua } \\
\text { aframbuesada } \\
\text { y conjuntivitis }\end{array}$ & $\begin{array}{c}\text { Líneas de } \\
\text { Beau en uñas } \\
\text { con posterior } \\
\text { descamación, } \\
\text { uso de tampo- } \\
\text { nes vaginales } \\
\text { o copas } \\
\text { menstruales }\end{array}$ \\
\hline $\begin{array}{l}\text { Choque tóxico por } \\
\text { estreptococo }\end{array}$ & $\begin{array}{c}\text { Erupción } \\
\text { eritematosa } \\
\text { poco frecuente }\end{array}$ & & $\begin{array}{l}\text { Descamación } \\
\text { palmo-plantar } \\
\text { poco frecuente }\end{array}$ & $\begin{array}{l}\text { Vesículas } \\
\text { y ampollas } \\
\text { violáceas } \\
\text { localizado } \\
\text { a sitio de } \\
\text { infección }\end{array}$ & & & & $\begin{array}{l}\text { Dolor en } \\
\text { extremidad }\end{array}$ \\
\hline $\begin{array}{l}\text { Sífilis secundaria } \\
\text { (T. pallidum) }\end{array}$ & Sí & & $\begin{array}{c}\text { Roséola } \\
\text { sifilítica } \\
\text { con rodete } \\
\text { descamativo }\end{array}$ & & $\begin{array}{l}\text { Diseminado, } \\
\text { simétrico, } \\
\text { afecta palmas } \\
\text { y plantas } \\
\text { No pruriginoso }\end{array}$ & & $\begin{array}{c}\text { Úlceras } \\
\text { superficiales } \\
\text { pequeñas } \\
\text { hasta placas } \\
\text { grisáceas. } \\
\text { Pápulas } \\
\text { y nódulos } \\
\text { comisura bucal }\end{array}$ & $\begin{array}{c}\text { Antecedente } \\
\text { de ulceración } \\
\text { genital 3-4 } \\
\text { semanas antes } \\
\text { Formas eritema } \\
\text { figurado y } \\
\text { alopecia no } \\
\text { cicatrizal }\end{array}$ \\
\hline $\begin{array}{l}\text { Meningococemia } \\
\text { (N. meningitidis) }\end{array}$ & & & $\begin{array}{l}\text { Morbiliforme } \\
\text { transitoria }\end{array}$ & & $\begin{array}{c}\text { Inicio } \\
\text { generalizado }\end{array}$ & $\begin{array}{c}\text { Palpable, } \\
\text { petequias, } \\
\text { foliculitis } \\
\text { hemorrágica }\end{array}$ & & $\begin{array}{l}\text { Las placas } \\
\text { purpúricas } \\
\text { evolucionan } \\
\text { a nódulos } \\
\text { dolorosos }\end{array}$ \\
\hline $\begin{array}{l}\text { Sepsis } \\
\text { neumocócica (S. } \\
\text { pneumoniae) }\end{array}$ & & & & & & $\begin{array}{c}\text { Petequias } \\
\text { diseminadas }\end{array}$ & & \\
\hline $\begin{array}{l}\text { Tifoidea } \\
\text { (Salmonella typhi) }\end{array}$ & & & Roséola tífica & $\begin{array}{c}\text { Ampollas } \\
\text { hemorrágicas }\end{array}$ & & & & $\begin{array}{c}\text { Eritema } \\
\text { polimorfo }\end{array}$ \\
\hline $\begin{array}{l}\text { Infección por } \\
\text { leptospira }\end{array}$ & & & & & & $\begin{array}{l}\text { Petequias y } \\
\text { hemorragias } \\
\text { purpúricas }\end{array}$ & & Descamación \\
\hline $\begin{array}{l}\text { Infección por } \\
\text { micoplasma }\end{array}$ & & Generalizado & & & Generalizado & & & $\begin{array}{l}\text { Eritema } \\
\text { polimorfo }\end{array}$ \\
\hline $\begin{array}{l}\text { Enfermedad } \\
\text { de Lyme }(B \text {. } \\
\text { burgdorferi) }\end{array}$ & $\begin{array}{c}\text { Migratorio. } \\
\text { Placa } \\
\text { eritematosa } \\
\text { de crecimiento } \\
\text { centrífugo o } \\
\text { lesión en diana }\end{array}$ & & & Puede ser & $\begin{array}{l}\text { Diseminado } \\
\text { extremidades }\end{array}$ & & & \\
\hline COVID-19 & $\begin{array}{l}\text { Palmas y } \\
\text { plantas }\end{array}$ & Sí & $\begin{array}{l}\text { Comprendido } \\
\text { en otros } \\
\text { exantemas }\end{array}$ & Sí & Sí & Sí & Rara & $\begin{array}{l}\text { Seudosaba- } \\
\text { ñones }\end{array}$ \\
\hline
\end{tabular}


No todos los pacientes incluidos en la casuística tuvieron pruebas PCR + o alguna otra prueba positiva relacionada con la enfermedad, ${ }^{21}$ en el artículo también se establece una relación temporal entre la aparición de los traumatismos cutáneos y el tiempo de evolución de la COVID-19.

La urticaria y los exantemas maculopapulares o vesiculares podrían presentarse desde seis días antes de las señales respiratorias o gastrointestinales, durante la primera y segunda semanas de evolución. Los exantemas purpúricos, livedoides y los seudosabañones son erosiones esencialmente tardías, pudiendo aparecer hasta 45 días después de los síntomas de la enfermedad con cualquier morfología.

También han sido descritos cuadros, similares a reacciones a fármacos, o asociadas a otras virosis: eritema polimorfo, ${ }^{22}$ pustulosis aguda exantemática, ${ }^{22,23}$ síndrome SDRIFE (exantema intertriginoso y flexural por fármacos), ${ }^{24}$ lesiones purpúricas o ampollosas con histología de vasculitis leucocitoclástica, ${ }^{25}$ enfermedad de Kawasaki-like ${ }^{26}$ DRESS: erupción dermatológica, eosinofilia y síntomas sistémicos, ${ }^{27}$ pitiriasis rosada-like, ${ }^{28}$ deterioros en mucosas: oral, genital y ocular. ${ }^{29,30}$ Se requiere un sexto grupo a fin de incluir todos los cuadros.

En cuanto a la topografía, el tórax fue sin duda la región más afectada, seguido de las extremidades con predilección en localizaciones acrales manos y pies. La afección de cara y cuello es rara. ${ }^{31-33}$

La serie más grande con la que se cuenta es la de Daneshgaran y colegas, ${ }^{20}$ una revisión multinacional de 996 casos de los cuales $54.3 \%$ eran mujeres, con una edad promedio de 37.3 años. El 58.2\% tenían algún estudio de laboratorio positivo para SARS-CoV-2. En esta serie, las lesiones en las zonas acrales, sin especificar de qué tipo, fueron las más frecuentes con $40.4 \%$, el exantema maculopapular $21.3 \%$, exantema vesicular $13 \%$, exantema urticariano $10.9 \%$. Freeman y asociados ${ }^{31}$ reunieron 716 sucesos, todos con algún estudio positivo en relación al virus (PCR, IgM o IgG). El exantema maculopapular fue el más frecuente con un $22 \%$, eritema pernio o seudosabañones en un $18 \%$, urticaria $16 \%$, eritema macular $13 \%$, vesicular $11 \%$, papuloescamoso $9.9 \%$, púrpura y ulceraciones livedoides en $6.4 \%$. Casi todas estas publicaciones reportan casos de enfermos hospitalizados.

La Academia Mexicana de Dermatología ${ }^{34}$ presentó, en su webinar del mes de agosto de 2020, una casuística de 125 pacientes de diferentes regiones del país, concluyendo que en enfermos mexicanos las manifestaciones más frecuentes son: el exantema maculopapular 25.9\%, urticaria y angioedema $22.4 \%$, exantema vesicular $15.2 \%$, lesiones purpúricas y livedoides aproximadamente $10 \%$, seudosabañones y eritema pernio $10 \%$ (datos no publicados).

Los dermatólogos quienes trabajan en hospitales privados o en la consulta externa, no han tenido oportunidad de ver personas afectadas con abrasiones livedoides y necróticas asociadas a la gravedad de la enfermedad. El cuadro comparativo con otras series, incluyendo la de los autores están en la Tabla 5.

Con el confinamiento, la telemedicina adquirió un papel muy importante buscando el diagnóstico a distancia, difícil, pues la calidad de las imágenes recibidas no fue óptima. Ya sea en forma presencial o por teleconsultas, se lograron reunir 33 casos con manifestaciones cutáneas relacionadas con COVID-19.

De los 33 incidentes que se presentan, no todos los enfermos tuvieron pruebas positivas a pesar de que sus cuadros clínicos eran altamente sugestivos, es muy probable que se deba al tiempo que había transcurrido entre la enfermedad y la toma de las muestras. Algunos de los

Tabla 3: Comparación COVID-19 con otras enfermedades bacterianas raras.

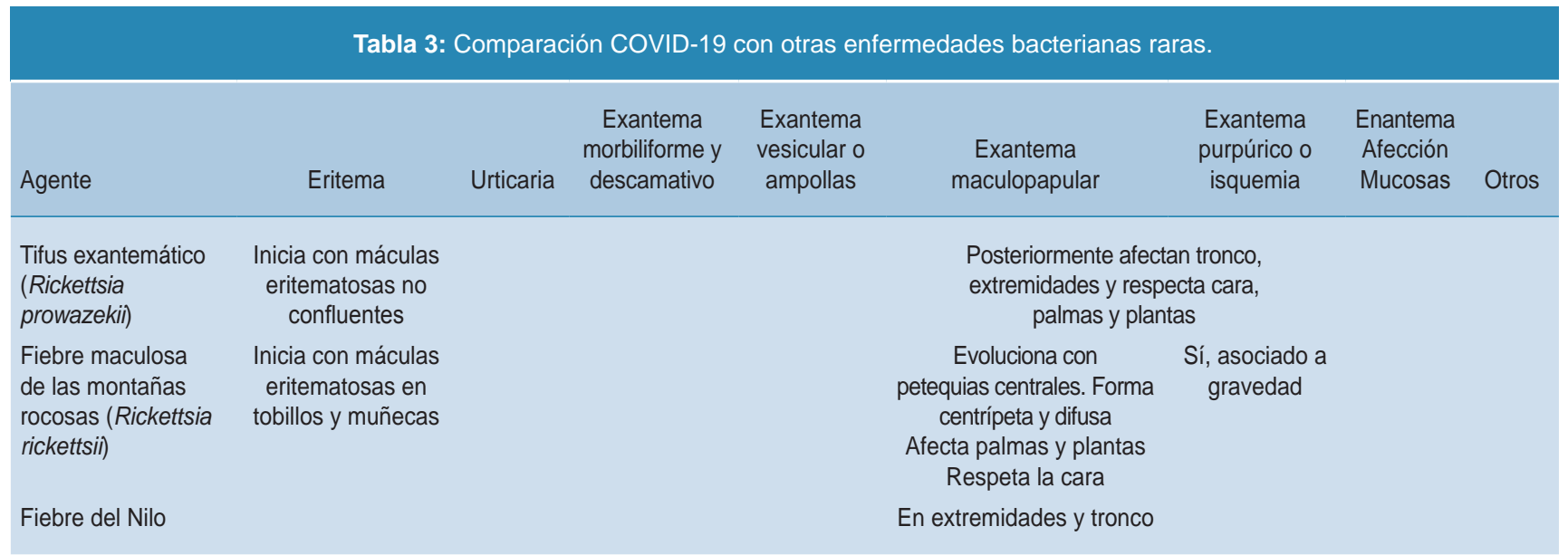


Tabla 4: Comparación COVID-19 y otras enfermedades inflamatorias, medicamentosas y autoinmunes.

\begin{tabular}{|c|c|c|c|c|c|c|c|c|}
\hline Agente & Eritema & Urticaria & $\begin{array}{c}\text { Exantema } \\
\text { morbiliforme y } \\
\text { descamativo }\end{array}$ & $\begin{array}{l}\text { Exantema } \\
\text { vesicular o } \\
\text { ampollas }\end{array}$ & $\begin{array}{l}\text { Exantema ma- } \\
\text { culopapular }\end{array}$ & $\begin{array}{l}\text { Exantema } \\
\text { purpúrico o } \\
\text { isquemia }\end{array}$ & $\begin{array}{l}\text { Enantema } \\
\text { Afección } \\
\text { Mucosas }\end{array}$ & Otros \\
\hline $\begin{array}{l}\text { Síndrome de } \\
\text { Gianotti-Crosti }\end{array}$ & & & & & $\begin{array}{c}\text { Pápulas } \\
\text { pequeñas, } \\
\text { monomorfas, } \\
\text { color rojo } \\
\text { pardo o } \\
\text { cobrizo, } \\
\text { firmes en } \\
\text { cara, orejas, } \\
\text { nalgas y } \\
\text { extremidades }\end{array}$ & & & $\begin{array}{c}\text { Fenómeno } \\
\text { de } \\
\text { Koebner }\end{array}$ \\
\hline $\begin{array}{l}\text { Exantema torácico } \\
\text { y periflexural de la } \\
\text { infancia }\end{array}$ & Sí & & & & $\begin{array}{c}\text { Inicia } \\
\text { unilateral en } \\
\text { axila o ingle y } \\
\text { se disemina }\end{array}$ & & & \\
\hline $\begin{array}{l}\text { Artritis idiopática } \\
\text { juvenil }\end{array}$ & & & & & $\begin{array}{l}\text { Color salmón, } \\
\text { en tronco y } \\
\text { extremidades }\end{array}$ & & & $\begin{array}{l}\text { Linfadeno- } \\
\text { patía } \\
\text { Hepatoes- } \\
\text { plenome- } \\
\text { galia }\end{array}$ \\
\hline $\begin{array}{l}\text { Lupus eritematosos } \\
\text { sistémico }\end{array}$ & $\begin{array}{l}\text { Eritema malar } \\
\text { en "alas de } \\
\text { mariposa" }\end{array}$ & $\begin{array}{l}\text { En formas } \\
\text { crónicas }\end{array}$ & & Sí, con úlceras & & & $\begin{array}{l}\text { Fenómeno de } \\
\text { Raynaud } \\
\text { Lupus pernio }\end{array}$ & \\
\hline Púrpura de Henoch & & Ocasional & & $\begin{array}{l}\text { Vesículas y } \\
\text { ampollas }\end{array}$ & & $\begin{array}{c}\text { Diseminado } \\
\text { en tronco y } \\
\text { extremidades } \\
\text { inferiores } \\
\text { Purpura } \\
\text { palpable }\end{array}$ & & $\begin{array}{c}\text { Distribuida } \\
\text { en nalgas } \\
\text { piernas } \\
\text { y zonas } \\
\text { extensoras }\end{array}$ \\
\hline $\begin{array}{l}\text { Enfermedad injerto } \\
\text { contra huésped }\end{array}$ & & & & $\begin{array}{c}\text { Estadio IV } \\
\text { Eritrodermia } \\
\text { con ampollas }\end{array}$ & $\begin{array}{c}\text { Estadio 1: } \\
\text { menos } 25 \% \\
\text { superficie } \\
\text { corporal } \\
\text { Estadio 2: } \\
25-50 \% \\
\text { estadio 3: } \\
\text { más } 50 \% \text { o } \\
\text { eritrodermia }\end{array}$ & & & \\
\hline Medicamentosas & & $\begin{array}{c}\text { Penicilina } \\
\text { Cefalospo- } \\
\text { rinas } \\
\text { AINEs } \\
\text { Anticuerpos } \\
\text { Monoclonales } \\
\text { y medios de } \\
\text { contraste }\end{array}$ & $\begin{array}{l}\text { Penicilinas } \\
\text { Cefalospo- } \\
\text { rinas } \\
\text { Anticonvulsi- } \\
\text { vantes } \\
\text { Alopurinol } \\
\text { Sulfonamidas }\end{array}$ & $\begin{array}{l}\text { NET y SSJ } \\
\text { Sulfonamidas } \\
\text { Anticonvulsi- } \\
\text { vantes } \\
\text { AINEs } \\
\text { Alopurinol }\end{array}$ & $\begin{array}{l}\text { Pustulosis } \\
\text { exantemática } \\
\text { Macrólidos } \\
\text { Beta } \\
\text { lactámicos } \\
\text { Calcio- } \\
\text { antagonistas }\end{array}$ & $\begin{array}{l}\text { Vasculitis: } \\
\text { Penicilinas } \\
\text { AINEs } \\
\text { Sulfonamidas } \\
\text { Cefalospo- } \\
\text { rinas } \\
\text { Antihiperten- } \\
\text { sivos } \\
\text { Alopurinol } \\
\text { Quinolonas } \\
\text { Tiazida }\end{array}$ & & \\
\hline
\end{tabular}

casos de este estudio ocurrieron al inicio de la pandemia, cuando aún no había suficientes lugares donde hacer pruebas, los requisitos eran rigurosos, el precio elevado y las lesiones cutáneas no estaban contempladas como parte de la enfermedad (Figura 2).

\section{URTICARIA Y ANGIOEDEMA EN COVID-19}

Es de todos conocido que algunos cuadros de urticaria aguda pueden ser provocados por infecciones. La COVID-19 no es la excepción. Las mucosas son el sitio de entrada del 
virus y los mastocitos podrían reaccionar a las proteínas virales en forma temprana. Las manifestaciones clínicas son habones y eritema fugaces, pueden o no tener un halo blanquecino y ser localizados o diseminados, en general son muy pruriginosos.

Se presentan en el 10.9 al $22.4 \%$ de los casos, dependiendo de la serie. ${ }^{11,20-22,32-35}$ En la casuística mexicana se ha encontrado hasta en un $22.4 \% .{ }^{34}$ Las lesiones han aparecido antes de los síntomas o durante la enfermedad y son muy sospechosas de COVID-19 si además están acompañadas de fiebre. ${ }^{35-37}$ Está reportada la asociación con angioedema ${ }^{37}$ y rarezas como el caso de dos miembros de la misma familia con daños de este tipo a modo de manifestaciones tempranas de la infección. ${ }^{38}$ Es raro que se tomen biopsias de lesiones así, sin embargo, se han comunicado casos con hallazgos de dermatitis de interfaz e infiltrados linfo- y neutrofílicos perivasculares en dermis superficial. ${ }^{39,40}$

La urticaria se ha asociado a enfermedad severa, pudiendo formar parte de un síndrome multisistémico con fiebre, dolor abdominal, diarrea, alteraciones del ritmo cardiaco, hepatitis, alteraciones neurológicas y enfermedad respiratoria. También se han visto formas de urticariavasculitis, en esta versión las alteraciones persisten más de 24 horas y pueden ser dolorosas, tendiendo a dejar una leve púrpura residual y transitoria. La biopsia revela vasculitis leucocitoclástica de medianos vasos. Esto parece ser una manifestación de tormenta de citoquinas y podría considerarse un signo de alarma. ${ }^{40,41} \mathrm{Si}$ las lesiones aparecen acompañadas de los síntomas sistémicos y el paciente se encuentra hospitalizado, es necesario descartar los medicamentos como agentes causales, al igual que otras causas de urticaria.

Es necesario señalar que la virosis puede también exacerbar casos de urticaria crónica y éstas persistir por semanas después de la enfermedad. Habitualmente, responden bien al tratamiento con antihistamínicos y esteroides en caso necesario. Rodríguez-Jiménez y colaboradores ${ }^{40}$ describieron un caso de una paciente que presentó lesiones urticarianas, tenía además neumonía bilateral, leucopenia, elevación de transaminasas y marcadores de inflamación elevados. La biopsia reveló una dermatitis de interfaz, con algunos queratinocitos necróticos. La evolución fue tórpida y desarrolló después vesículas. Concluyen que las erupciones urticarianas pueden ser el cuadro inicial de la COVID-19 y que van evolucionando a otros más complicados desde el punto de vista clínico, fisiopatológico e histológico, con pronóstico variable. ${ }^{40-42}$

\section{EXANTEMA MACULOPAPULAR}

Basados en las grandes series publicadas hasta el momento, el exantema macular (morbiliforme), maculopapular o papulomacular y escamoso, son el evento que con más frecuencia se presenta asociado con la COVID-19. En la literatura corresponde al segundo lugar entre las lesiones causadas por SARS-CoV-2, aparentemente precedida por los seudosabañones. ${ }^{4,11,20-22,32-34,41,42}$

El exantema maculopapular puede aparecer previo a los síntomas respiratorios, durante la primera o segunda semanas de la enfermedad y también se ha visto hasta 45 días después del diagnóstico. Esto hace pensar que la fisiopatología puede cambiar durante la historia natural de la virosis en donde la carga viral y los elementos de inmunidad juegan un papel importante siendo primordial descartar las reacciones medicamentosas.

Las series reportadas no muestran una idea clara en cuanto a su frecuencia y su tiempo de aparición, pues la descripción del exantema es muy confusa. ${ }^{20,21}$ En el estudio de Daneshgaran D. y colegas, quienes reúnen la mayor serie de casos, hay tres distintas clases que deben estar comprendidas en una sola:

Exantema maculopapular, exantema eritematoso no definido y el exantema "eritema polimorfo-like". ${ }^{20} \mathrm{Si}$ se toma como única la denominada exantema maculopapular, se ha visto que en $5.9 \%$ se presentan en forma temprana,

Tabla 5: Comparación de la presentación de las lesiones cutáneas en enfermos con COVID-19 en diferentes series.

\begin{tabular}{|c|c|c|c|c|c|c|}
\hline & $\mathrm{n}$ & $\begin{array}{c}\text { Eritema maculopapular } \\
\text { y escamoso (\%) }\end{array}$ & $\begin{array}{c}\text { Exantema } \\
\text { vesicular (\%) }\end{array}$ & Urticaria (\%) & $\begin{array}{c}\text { Purpúrico } \\
\text { livedoide (\%) }\end{array}$ & $\begin{array}{c}\text { Seudosabañón } \\
(\%)\end{array}$ \\
\hline Galván Casas C et al. ${ }^{21}$ & 375 & 47 & 9 & 19 & 6 & 19 \\
\hline Freeman EE et al. ${ }^{31}$ & 716 & 22 & 11 & 16 & 6 & 18 \\
\hline $\begin{array}{l}\text { AMD (Academia Mexicana } \\
\text { de Dermatología) }\end{array}$ & 125 & 26 & 15 & 22 & 16 & 8 \\
\hline Daneshgaran et al. ${ }^{20}$ & 996 & 21 & 13 & 11 & 40 & 40 \\
\hline $\begin{array}{l}\text { Colmexiderma } \\
\text { Ángeles Pedregal }\end{array}$ & 33 & 37 & 18 & 19 & 7 & 7 \\
\hline
\end{tabular}




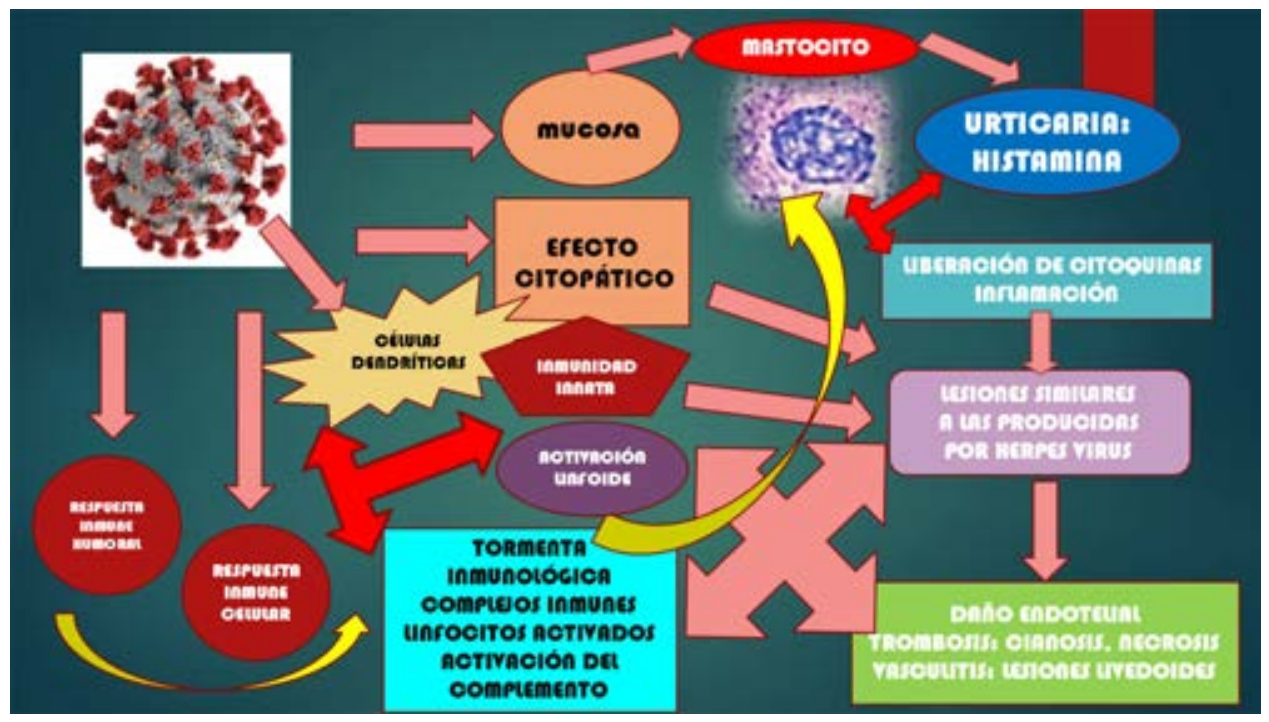

Figura 1:

Fisiopatología de las lesiones cutáneas por SARS-CoV-2 y génesis de lesiones cutáneas.

58.8\% aparecen simultáneos a los indicios característicos de COVID-19 y 34.6\% después. Los exantemas eritematosos no definidos aparecen antes de los síntomas, 28.6\% durante y $71.4 \%$ después. Su duración es entre tres y 18 días. ${ }^{42,43}$ Es importante tomar en cuenta que el exantema maculopapular puede ser el marcador de inicio del padecimiento y se debe siempre sospechar COVID-19. ${ }^{43}$ Desgraciadamente, no todos los casos tienen PCR + y alrededor del 50\% son negativos. Es capital la vigilancia de los enfermos, por la posibilidad de su capacidad de transmitir la infección, del mismo modo que su estudio en relación a otros diagnósticos; hay que recordar que existen numerosos virus, bacterias y parásitos que pueden causar este tipo de reacciones. Mención importante es la sífilis secundaria, que al igual que la COVID-19 es la gran imitadora. ${ }^{1-4}$

Las lesiones aparecen en el tronco y región proximal de las extremidades, el prurito acompaña a dos de cada tres pacientes. La morfología del exantema está compuesto por máculas, pápulas eritematosas a menudo confluentes, y ocasionalmente placas eccematoides. ${ }^{11,43-45}$ La afección de las mucosas es rara.

Histológicamente, existe una dermatitis con daño a la unión dermoepidérmica, infiltración por linfocitos en dermis superficial y profunda de predominio perivascular; recientemente, se encontró en los conductos y glándulas sudoríparas dilatación vascular con extravasación de eritrocitos; también se ha visto disqueratosis y datos de vasculitis linfocítica. Existen protocolos para marcar las proteínas virales (spike) en la piel de las lesiones, pero aún no se ha encontrado una interpretación adecuada de su hallazgo, hasta el momento se ha interpretado como contacto con el virus. Algunos patrones sugieren vasculitis linfocítica. ${ }^{43-47}$
Recientemente se han estado presentando casos de exantemas tardíos, algunos han iniciado vesiculares, posteriormente desarrollan maculopápulas confluentes que se extienden rápidamente y posteriormente descaman. ${ }^{46}$ Habitualmente no tienen fiebre ni síntomas generales, pero podrían desarollar leucocitosis, eosinofilia, elevación de transaminasas.

Cuadros similares al síndrome de hipersensibilidad (DRESS), ${ }^{27}$ pustulosis subcórnea aguda ${ }^{22,23}$ eritema polimorfo $^{22}$ y de otro tipo como SDRIFE ${ }^{26}$ pueden ser secundarios a los medicamentos y quizá pudieran deberse a la reactivación de herpes 6 y 7 , pero por el momento no hay la tecnología para detectarlo. ${ }^{28}$

Los pacientes que han padecido COVID-19 habitualmente han recibido hidroxicloroquina, azitromicina, paracetamol, lopinavir o ritonavir, tocilizumab, glucocorticoides, ivermectina, nitazoxanida y anticoagulantes. Se debe hacer una investigación profunda acerca de los medicamentos recibidos, muchas veces ellos estuvieron hospitalizados e ignoran del todo lo que les dieron.

Aproximadamente el 30\% de los enfermos tienen reacciones a medicamentos, a uno o a múltiples fármacos; tienen prueba epicutánea positiva, ${ }^{48}$ lo que podría ser de ayuda para diferenciarlas.

Se desconoce a ciencia cierta si estas reacciones tienen elementos de patología viral directa, si existen complejos inmunes involucrados y el papel que juegan los medicamentos o si su aparición es producto de todo lo anterior.

\section{EXANTEMA VESICULAR}

Esta dermatosis se caracteriza por ser monomorfa, vesículas sobre base eritematosa que varían entre dos a $5 \mathrm{~mm}$, y pueden ser localizadas o diseminadas. ${ }^{49}$ 
Dentro de la casuística de Marzano y colaboradores, ${ }^{50}$ observaron 22 casos de erupción variceliforme los cuales contaban con PCR+, siendo de mayor prevalencia en hombres con una edad promedio de 60 años. Dentro de la evolución clínica, las lesiones se presentaron en forma simultánea e incluso precedían a los síntomas generales y respiratorios de COVID-19. ${ }^{49-51}$

En la literatura, se encuentran diversos reportes de exantemas vesiculosos, también llamados "varicela-like", para los autores, al igual que para Mahé y colaboradores, es importante remarcar que los deterioros vesiculosos no guardan similitud con la varicela. ${ }^{49,50,52}$

El hallazgo clínico de excelencia, en la infección por virus de varicela zóster, es la aparición de lesiones en diferente estado de evolución que afectan a todo el cuerpo, incluyendo la piel cabelluda y la cara. A diferencia de las manifestaciones cutáneas de infección por SARS-CoV-2, donde las heridas se observan con mayor frecuencia en tronco, extremidades y cuello, es muy rara la afección de la cabeza. Otra diferencia entre estas entidades es que las vesículas tienden a reventarse y formar abrasiones secundarias de tipo costroso, en el caso de la varicela, evolucionan de vesícula a pústula y de ahí a la costra. ${ }^{1-4}$ Las lesiones vesiculosas generalmente se acompañan de prurito, y en menor frecuencia de dolor $u$ otras manifestaciones agregadas. ${ }^{21,49}$ No son infectantes, ya que los virus RNA no pueden reproducirse en células epidérmicas como los virus DNA. Esto fue estudiado por Fernández-Nieto, buscando

Figura 2: Frecuencia de manifestaciones cutáneas en nuestra casuística.

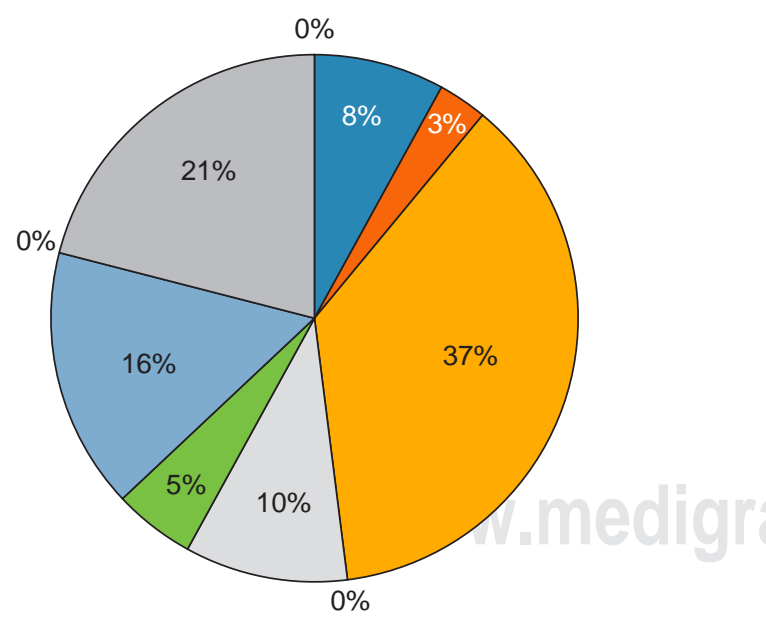

Urticaria

Purpura e isquemia

Exantema maculopapular Exantema

Exantema maculo vesicular

Pseudo sabañon
SARS-CoV-2 y VVZ directo en las ampollas de los enfermos de COVID-19.51

En la serie de casos publicada por Fernández-Nieto y colaboradores, ${ }^{51}$ se habla de dos patrones: diseminado y localizado, siendo el patrón diseminado el más frecuente con el $75 \%$ de pacientes pudiendo presentar ulceraciones en diferente estado de evolución, en tanto que el localizado exhibe lesiones vesiculosas monomorfas.

Histológicamente, Mahé observó vesículas intraepidérmicas o suprabasales uniloculares con acantólisis no balonizante, disqueratosis eosinofílica con aspecto "pomegranatelike" ${ }^{52,53}$ El grupo de Fernández-Nieto encontró más efectos balonizantes que Mahé, y con ayuda de herramientas moleculares como la inmunohistoquímica, pudo hallar proteínas virales de SARS-CoV-2 en el endotelio de los vasos. ${ }^{53}$

A pesar de los diversos estudios y múltiples hipótesis, aún no se cuenta con la información necesaria para entender con mayor exactitud la fisiopatología de esta manifestación cutánea, así como la relación con la evolución clínica del paciente y los desenlaces posibles.

\section{LESIONES ACRALES: SEUDOSABAÑONES O DEDOS COVID}

Las lesiones inflamatorias acrales fueron reportadas por varios grupos de dermatólogos europeos, principalmente en Francia, donde la comunicación por medios digitales hizo circular miles de fotografías por WhatsApp..$^{53}$ Más de 140 fotografías de dermatólogos privados que vieron casos leves de COVID-19 reportaron seudosabañones. Los dermatólogos españoles reportaron en su gran serie un grupo de niños y adultos jóvenes con una media de 14 años. Son alteraciones eritemato-violáceas alrededor de las uñas de las manos y los pies (seudosabañones o dedos COVID-19). ${ }^{21}$

Habitualmente, las desarrollan pacientes que tuvieron contacto con personas contagiadas, no tienen sintomatología respiratoria ni digestiva asociada, tienen PCR- y no presentan anticuerpos IgG, no contagian la enfermedad. Es más frecuente en mujeres que en hombres y son escasos los que presentan síntomas generales, $5 \%$ fiebre y ocasionalmente diarrea. ${ }^{33}$

La serie de Galván-Casas y colegas $^{21}$ muestra una frecuencia del 19\% del total de lesiones relacionadas a COVID-19. Se describen desde pequeñas pápulas eritematoedematosas de milímetros de diámetro hasta grandes placas que afectan toda una falange. Se presentan más en los pies (84\%) que en las manos (5.1\%), 10\% en ambos sitios. También se han descrito en talones y codos. Pueden ser únicas o múltiples. Son susceptibles de presentarse como eritema acral 30\%, dactilitis 20\%, maculopápulas en 35\% y patrones mixtos en un $15 \% .{ }^{54,55}$ El edema está presente 
en el 36.4\% de los casos, pudiéndose encontrar vesículas hemorrágicas. Se ha descrito la sensación de quemadura o ardor hasta en un 54.4\%, el prurito está presente en un $30 \%$, en 20 a $27 \%$ de los eventos son asintomáticos. Su duración es de aproximadamente 12.5 días. ${ }^{13,14,34,35,43,44}$ Se describe que $69.7 \%$ de los afectados no cursan con ningún síntoma general y sólo el $30.3 \%$ presentaron alguno como astenia, adinamia, tos, diarrea, fiebre, mialgia, cefalea y odinofagia. Parecen afectar con mayor frecuencia a mujeres que a hombres (68\% versus $32 \%$ ). Rara vez elevan los indicadores de inflamación sistémica. Habitualmente su aparición es tardía, se inicia a las tres semanas de haberse presentado un contacto con un infectado o de haber comenzado los propios síntomas. ${ }^{11}$

Andina y colaboradores ${ }^{55}$ estudiaron 22 pacientes con seudosabañones. Encontraron una media etaria de 12 años. La aparición de las lesiones después del contacto, o de la infección por SARS-CoV-2 fue de uno a 28 días con media de siete días.

Ningún paciente tenía antecedentes de enfermedades reumáticas como lupus eritematoso, esclerodermia, enfermedad mixta del tejido conectivo, fenómeno o enfermedad de Reynaud, acrocianosis por crioglobulinas o previa historia de sabañones. Se presentó prurito y dolor moderado en $9.41 \%$ y $7.32 \%$ respectivamente. Diez enfermos presentaron algún síntoma respiratorio como tos o rinorrea, nueve pacientes $41 \%$ dolor abdominal o diarrea y dos más tenían una combinación de ambos síntomas. ${ }^{56}$

Freeman y su equipo ${ }^{57}$ estudiaron 505 casos de daños cutáneos de COVID-19 y encontraron 318 incidentes de lesiones pernio-like, pacientes jóvenes con un promedio de edad de 25 años. Sólo el 7\% tuvieron PCR, IgM o IgG positiva. Todos habían tenido contacto reciente con contagiados con enfermedad COVID. Otras señales estuvieron presentes en $45 \%$ de ellos; $21 \%$ tos, odinofagia en $12 \%$ y fiebre moderada en $12 \%$. Las lesiones se presentaron antes de los síntomas en el $13 \%, 15 \%$ al mismo tiempo y $54 \%$ al final o posterior. Los indicios fueron leves en la mayoría, sólo seis pacientes fueron hospitalizados, cuatro sobrevivieron y dos murieron. No parece ser tan inocuo como se pensaba. ${ }^{58,59}$

Al parecer, estas manifestaciones aparecen por el efecto de la liberación de múltiples citoquinas que inducen vasculitis y microangiopatía. El daño endotelial es mediado por citoquinas y depósito de complemento, que favorece la presencia de trombos hialinos en vasos de pequeño calibre. Histológicamente se observa edema de la dermis, infiltrado linfoide angiocéntrico, así como degeneración de la membrana basal, exocitosis de linfocitos a la epidermis y las glándulas sudoríparas de tipo écrino con predilección por el acrosiringio. ${ }^{59}$

Ramondetta y colegas $^{58}$ afirman que la cantidad de pacientes con lesiones inflamatorias acrales, similares al eritema pernio idiopático (causado por frío), fue realmente anormal durante lo que va de la pandemia, aun cuando ésta inició en los meses fríos del año. Se observaron varios sucesos, inclusive en la misma familia, con deterioros similares y un raro incremento de los casos pediátricos. ${ }^{60}$

Hay autores como Herbert, Locatelli, Docampo y colaboradores $^{12,13,57}$ que han estudiado las lesiones inflamatorias acrales desde el punto de vista histológico, inmunohistoquímico y serológico en sujetos sospechosos de contacto o haber padecido COVID-19. Sus hallazgos revelaron que los seudosabañones tienen pocas posibilidades de relacionarse con esta enfermedad. Los principales argumentos son que en estos enfermos la PCR es negativa, quizá esto se deba a que es una manifestación tardía o bien que la carga viral no es suficiente para dar una prueba de PCR+; además pocos sufren seroconversión. La mayoría de los enfermos son niños o adultos jóvenes, son paucisintomáticos, y la aparición de las heridas ha coincidido con el invierno europeo, quizá por ello se relacionó con tanta frecuencia.

Kanitakis y Herman ${ }^{59}$ estudiaron la presencia de antígenos de SARS-CoV-2 en las biopsias de más de 30 sospechosos y no encontraron proteínas virales. ${ }^{60}$

El Hachem y colegas $^{13}$ hicieron video-capilaroscopia en 19 enfermos con lesiones acrales sospechosas de COVID-19, encontrando edema, dilatación anormal de los capilares y microhemorragias. Dos de sus pacientes tuvieron SARS-CoV-2 positivo.

El $57.9 \%$ tuvieron edema postcapilar en las manos y $26.3 \%$ en los pies; la dimensión capilar anormal 36.8\% en manos y $36.8 \%$ en pies; la morfología fue anormal en el $73 \%$ en las manos y en $52.6 \%$ en los pies; por último, se encontraron microhemorragias $21 \%$ en manos y $36.8 \%$ en pies. En la inmunofluorescencia de 11 aquejados hubo depósito granular de C3 en la pared de los vasos de la dermis, cuerpos coloides en la unión dermoepidérmica, IgM positiva en cuatro casos y dos a IgG. La PCR negativa y la serología contra la nucleocápside fue negativa en todas las ocasiones, S1 positiva en un caso y limítrofe en tres.

A los pocos días, Colmenero y colaboradores ${ }^{16}$ reportaron los resultados del estudio de siete pacientes con seudosabañones y contacto con enfermos de COVID-19: cuatro hombres y tres mujeres. Encontraron infiltrado CD3+ con predominio de células $T$ ayudadoras (CD4) y linfocitos B maduros CD20+. Con microscopia electrónica, en un enfermo lograron ver una imagen sospechosa de presencia del virus y concluyen que, efectivamente, los seudosabañones son una manifestación de COVID-19. En este sentido, Gamblichler ${ }^{14}$ comunicó el caso de una mujer de 80 años con COVID-19 y neumonía, que desarrolló una lesión acral tres semanas después de haber iniciado los síntomas, el marcaje inmunohistoquímico para proteínas SARS-CoV-2 
fue positivo en las glándulas sudoríparas. Relacionan la lesión cutánea con el virus e inclusive proponen al sudor como una posible fuente de contagio.

En México, las lesiones acrales son raras, se desconoce la razón, aunque no hay publicaciones al respecto.

\section{CONCLUSIONES}

El virus SARS-CoV-2, aun cuando no se conoce la frecuencia con que afecta la piel, puede imitar múltiples cuadros virales, bacterianos, autoinmunes y reaccionales. La fisiopatología parece estar relacionada con el daño vascular causado por el virus. La presencia del virus en las ulceraciones cutáneas es controversial. Las lesiones podrían aparecer en cualquier momento de la enfermedad. En tiempo de pandemia, sospechar el diagnóstico de COVID-19 es clave para evitar su diseminación, pero al convivir con la enfermedad por tiempo prolongado, no se debe olvidar la enorme lista de diagnósticos diferenciales.

\section{REFERENCIAS}

1. Drago F, Ciccarese G, Gasparini G, Cogorno L, Javor S, Toniolo A et al. Contemporary infectious exanthems: an update. Future Microbiol. 2017; 12: 171-193. doi: 10.2217/fmb-2016-0147.

2. Kang JH. Febrile illness with skin rashes. Infect Chemother. 2015; 47 (3): 155-166.

3. Ely JW, Seabury Stone M. The generalized rash: part I. Differential diagnosis. Am Fam Physician. 2010; 81 (6): 726-734.

4. Muzumdar S, Rothe MJ, Grant-Kels JM. The rash with maculopapules and fever in adults. Clin Dermatol. 2019; 37 (2): 109-118.

5. Castillo SA, Pham AK, Dinulos JG. Cutaneous manifestations of systemic viral diseases in neonates: an update. Curr Opin Pediatr. 2017; 29 (2): 240-248.

6. Soman L. Fever with rashes. Indian J Pediatr. 2018; 85 (7): 528-534. doi: 10.1007/s12098-017-2459-1.

7. Watts Santos A, Ocampo Candiani J. Manifestaciones dermatológicas en dengue, zika y chikungunya. Dermatologia Cosmet Medica y Quir. 2019; 17 (1): 52-59.

8. Lipsker D. Paraviral eruptions in the era of COVID-19: Do some skin manifestations point to a natural resistance to SARS-CoV-2? Clin Dermatol. 2020; 38 (6): 757-761. doi: 10.1016/j.clindermatol.2020.06.005.

9. Kubanov AA, Deryabin DG. Skin manifestations in COVID-19 provide a clue for disease's pathophysiology understanding. J Eur Acad Dermatol Venereol. 2021; 35 (1): e3-e4. doi: 10.1111/jdv.16902.

10. Criado PR, Abdalla BMZ, de Assis IC, van Blarcum de Graaff Mello C, Caputo GC, Vieira IC. Are the cutaneous manifestations during or due to SARS-CoV-2 infection/COVID-19 frequent or not? Revision of possible pathophysiologic mechanisms. Inflamm Res. 2020; 69 (8): 745-756. doi: 10.1007/s00011-020-01370-w.

11. Carrascosa JM, Morillas V, Bielsa I, Munera-Campos M. Cutaneous manifestations in the context of SARS-CoV-2 infection (COVID-19). Actas Dermosifiliogr (Engl Ed). 2020; 111 (9): 734-742. doi: 10.1016/j. ad.2020.08.002.

12. Hébert V, Duval-Modeste AB, Joly P, Lemée V, Cellier L, Jouen F et al. Lack of association between chilblains outbreak and severe acute respiratory syndrome coronavirus 2 : histologic and serologic findings from a new immunoassay. J Am Acad Dermatol. 2020; 83 (5): 14341436. doi: 10.1016/j.jaad.2020.07.048.
13. El Hachem M, Diociaiuti A, Concato C, Carsetti R, Carnevale C, Ciofi Degli Atti M et al. A clinical, histopathological and laboratory study of 19 consecutive Italian paediatric patients with chilblain-like lesions: lights and shadows on the relationship with COVID-19 infection. J Eur Acad Dermatol Venereol. 2020; 34 (11): 2620-2629. doi: 10.1111/jdv.16682.

14. Gambichler T, Reuther J, Stücker M, Stranzenbach R, Torres-Reyes C, Schlottmann R, Schmidt WE, Hayajneh R, Sriram A, Becker JC." A review of dermatologic manifestations of coronavirus 2019 (COVID-19) disease" Dermatology Research and Practice :Volume 2020, Article ID 9360476, https://doi.org/10.1155/2020/9360476

15. Docampo-Simón A, Sánchez-Pujol MJ, Juan-Carpena G, PalazónCabanes JC, Vergara-De Caso E, Berbegal L et al. Are chilblain-like acral skin lesions really indicative of COVID-19? A prospective study and literature review. J Eur Acad Dermatol Venereol. 2020; 34 (9): e445-e447. doi: 10.1111/jdv.16665.

16. Colmenero I, Santonja C, Alonso-Riaño M, Noguera-Morel L, Hernández-Martín A, Andina D et al. SARS-CoV-2 endothelial infection causes COVID-19 chilblains: histopathological, immunohistochemical and ultrastructural study of seven paediatric cases. $\mathrm{Br} J$ Dermatol. 2020; 183 (4): 729-737. doi: 10.1111/bjd.19327.

17. Li Q, Guan X, Wu P, Wang X, Zhou L, Tong Y et al. Early transmission dynamics in Wuhan, China, of novel coronavirus-infected pneumonia. N Engl J Med. 2020; 382 (13): 1199-1207.

18. Joob B, Wiwanitkit V. COVID-19 can present with a rash and be mistaken for dengue. J Am Acad Dermatol. 2020; 82 (5): e177. doi: 10.1016/j.jaad.2020.03.036.

19. Recalcati S. Cutaneous manifestations in COVID-19: a first perspective. J Eur Acad Dermatol Venereol. 2020; 34 (5): e212-e213. doi: $10.1111 / j d v .16387$.

20. Daneshgaran G, Dubin DP, Gould DJ. Cutaneous manifestations of COVID-19: an evidence-based review. Am J Clin Dermatol. 2020; 21 (5): 627-639. doi: 10.1007/s40257-020-00558-4.

21. Galván Casas C, Catala A, Carretero Hernández G, Rodríguez-Jiménez P, Fernández-Nieto D, Rodríguez-Villa Lario A et al. Classification of the cutaneous manifestations of COVID-19: a rapid prospective nationwide consensus study in Spain with 375 cases. Br J Dermatol. 2020; 183 (1): 71-77. doi: 10.1111/bjd.19163.

22. Robustelli Test E, Vezzoli P, Carugno A, Raponi F, Gianatti A, Rongioletti $F$ et al. Acute generalized exanthematous pustulosis with erythema multiforme-like lesions induced by hydroxychloroquine in a woman with coronavirus disease 2019 (COVID-19). J Eur Acad Dermatol Venereol. 2020; 34 (9): e457-e459. doi: 10.1111/jdv.16613.

23. Ayatollahi A, Robati RM, Kamyab K, Firooz A. Late-onset AGEP-like skin pustular eruption following COVID-19: a possible association. Dermatol Ther. 2020; 33 (6): e14275. doi: 10.1111/dth.14275.

24. Chicharro P, Rodríguez-Jiménez P, Muñoz-Aceituno E, De Argila D, Muñoz-Hernández P, Llamas-Velasco M. SDRIFE-like rash associated with COVID-19, clinicopathological correlation. Australas J Dermatol. 2021; 62 (1): 88-89. doi: 10.1111/ajd.13444.

25. Caputo V, Schroeder J, Rongioletti F. A generalized purpuric eruption with histopathologic features of leucocytoclastic vasculitis in a patient severely ill with COVID-19. J Eur Acad Dermatol Venereol. 2020; 34 (10): e579-e581. doi: 10.1111/jdv.16737.

26. Labé P, Ly A, Sin C, Nasser M, Chapelon-Fromont E, Ben Said P et al. Erythema multiforme and Kawasaki disease associated with COVID-19 infection in children. J Eur Acad Dermatol Venereol. 2020; 34 (10): e539-e541. doi: 10.1111/jdv.16666.

27. Herman A, Matthews M, Mairlot M, Nobile L, Fameree L, Jacquet LM et al. Drug reaction with eosinophilia and systemic symptoms syndrome in a patient with COVID-19. J Eur Acad Dermatol Venereol. 2020; 34 (12): e768-e700. doi: 10.1111/jdv.16838.

28. Drago F, Ciccarese G, Rebora A, Parodi A. Human herpesvirus-6, -7, and Epstein-Barr virus reactivation in pityriasis rosea during COVID-19. J Med Virol. 2021; 93 (4): 1850-1851. doi: 10.1002/jmv.26549. 
29. Capocasale G, Nocini R, Faccioni P, Donadello D, Bertossi D, Albanese $M$ et al. How to deal with coronavirus disease 2019: A comprehensive narrative review about oral involvement of the disease. Clin Exp Dent Res. 2021; 7 (1): 101-108. doi: 10.1002/cre2.332.

30. Falkenhain-López D, Agud-Dios M, Ortiz-Romero PL, SánchezVelázquez A. COVID-19-related acute genital ulcers. J Eur Acad Dermatol Venereol. 2020; 34 (11): e655-e656. doi: 10.1111/jdv.16740.

31. Freeman EE, McMahon DE, Lipoff JB, Rosenbach M, Kovarik C, Desai SR et al. The spectrum of COVID-19-associated dermatologic manifestations: An international registry of 716 patients from 31 countries. J Am Acad Dermatol. 2020; 83 (4): 1118-1129. doi: 10.1016/j.jaad.2020.06.1016.

32. Rahimi H, Tehranchinia Z. A Comprehensive review of cutaneous manifestations associated with COVID-19. Biomed Res Int. 2020; 2020: 1236520. doi: 10.1155/2020/1236520.

33. Wollina U, Karadag AS, Rowland-Payne C, Chiriac A, Lotti T. Cutaneous signs in COVID-19 patients: a review. Dermatol Ther. 2020; 33 (5): e13549. doi: 10.1111/dth.13549.

34. Welsh E. Academia Mexicana de Dermatología webinar agosto 2020. Resultados preliminares no publicados a la fecha.

35. Quintana-Castanedo L, Feito-Rodríguez M, Valero-López I, Chiloeches-Fernández C, Sendagorta-Cudós E, Herranz-Pinto P. Urticarial exanthem as early diagnostic clue for COVID-19 infection. JAAD Case Rep. 2020; 6 (6): 498-499. doi: 10.1016/j. jdcr.2020.04.026.

36. van Damme C, Berlingin E, Saussez S, Accaputo O. Acute urticaria with pyrexia as the first manifestations of a COVID-19 infection. J Eur Acad Dermatol Venereol. 2020; 34 (7): e300-e301. doi: 10.1111/ jdv.16523.

37. Najafzadeh M, Shahzad F, Ghaderi N, Ansari K, Jacob B, Wright A. Urticaria (angioedema) and COVID-19 infection. J Eur Acad Dermatol Venereol. 2020; 34 (10): e568-e570. doi: 10.1111/jdv.16721.

38. Cepeda-Valdes R, Carrion-Alvarez D, Trejo-Castro A, Hernandez-Torre $\mathrm{M}$, Salas-Alanis J. Cutaneous manifestations in COVID-19: familial cluster of urticarial rash. Clin Exp Dermatol. 2020; 45 (7): 895-896. doi: 10.1111/ced.14290.

39. Algaadi SA. Urticaria and COVID-19: a review. Dermatol Ther. 2020; 33 (6): e14290. doi: 10.1111/dth.14290.

40. Rodríguez-Jiménez $P$, Chicharro P, De Argila D, Muñoz-Hernández P, Llamas-Velasco M. Urticaria-like lesions in COVID-19 patients are not really urticaria - a case with clinicopathological correlation. J Eur Acad Dermatol Venereol. 2020; 34 (9): e459-e460. doi: 10.1111/ jdv.16618.

41. Suchonwanit P, Leerunyakul K, Kositkuljorn C. Diagnostic and prognostic values of cutaneous manifestations in COVID-19. Dermatol Ther. 2020; 33 (4): e13650. doi: 10.1111/dth.13650.

42. Young S, Fernandez AP. Skin manifestations of COVID-19. Cleve Clin J Med. 2020. doi: 10.3949/ccjm.87a.ccc031.

43. Reymundo A, Fernáldez-Bernáldez A, Reolid A, Butrón B, Fernández-Rico P, Muñoz-Hernández P et al. Clinical and histological characterization of late appearance maculopapular eruptions in association with the coronavirus disease 2019. A case series of seven patients. J Eur Acad Dermatol Venereol. 2020; 34 (12): e755-e757. doi: $10.1111 / j d v .16707$.

44. Lavery MJ, Bouvier CA, Thompson B. Cutaneous manifestations of COVID-19 in children (and adults): A virus that does not discriminate. Clin Dermatol. 2020. doi: 10.1016/j.clindermatol.2020.10.020.

45. Goldust M, Abdelmaksoud A, Shuang Z, Xiang C, Navarini AA. Fever with rash in COVID-19: viral exanthema or secondary lesions? J Eur Acad Dermatol Venereol. 2020; 34 (9): e464-e465. doi: 10.1111/ jdv.16639.

46. Rosell-Díaz AM, Mateos-Mayo A, Nieto-Benito LM, Balaguer-Franch I, Hernández de la Torre-Ruiz E, Lainez-Nuez A et al. Hallazgos histopatológicos en lesiones cutáneas inducido por COVID-19: correlación clínico-patológica de los patrones dermatológicos de SARS-CoV-2: revisión de la literatura. J Eur Acad Dermatol Venereol. 2020; 34 (9): e464-e465. doi: 10.1111/jdv.16639.

47. Pereira N, Canelas MM, Santiago F, Brites MM, Goncalo M. Value of patch tests in clindamycin-related drug eruptions. Contact Dermatitis. 2011; 65 (4): 202-207.

48. Herrero-Moyano M, Capusan TM, Andreu-Barasoain M, AlcántaraGonzález J, Ruano-Del Salado M, Sánchez-Largo Uceda ME et al. A clinicopathological study of eight patients with COVID-19 pneumonia and a late-onset exanthema. J Eur Acad Dermatol Venereol. 2020; 34 (9): e460-e464. doi: 10.1111/jdv.16631.

49. Gottlieb M, Long B. Dermatologic manifestations and complications of COVID-19. Am J Emerg Med. 2020; 38 (9): 1715-1721. doi: 10.1016/j.ajem.2020.06.011.

50. Marzano AV, Genovese G, Fabbrocini G, Pigatto P, Monfrecola G, Piraccini BM et al. Varicella-like exanthem as a specific COVID-19associated skin manifestation: Multicenter case series of 22 patients. J Am Acad Dermatol. 2020; 83 (1): 280-285.

51. Fernandez-Nieto D, Ortega-Quijano D, Jimenez-Cauhe J, BurgosBlasco P, de Perosanz-Lobo D, Suarez-Valle A et al. Clinical and histological characterization of vesicular COVID-19 rashes: a prospective study in a tertiary care hospital. Clin Exp Dermatol. 2020; 45 (7): 872-875. doi: 10.1111/ced.14277.

52. Mahé A, Birckel E, Merklen C, Lefebvre P, Hannedouche C, Jost $\mathrm{M}$ et al. Histology of skin lesions establishes that the vesicular rash associated with COVID-19 is not 'varicella-like'. J Eur Acad Dermatol Venereol. 2020; 34 (10): e559-e561. doi: 10.1111/jdv.16706.

53. Duong TA, Velter C, Rybojad M, Comte C, Bagot M, Sulimovic L et al. Did Whatsapp ${ }^{\circledR}$ reveal a new cutaneous COVID-19 manifestation? J Eur Acad Dermatol Venereol. 2020; 34 (8): e348-e350. doi: 10.1111/ jdv.16534.

54. Marraha F, Al Faker I, Gallouj S. A review of the dermatological manifestations of coronavirus disease 2019 (COVID-19). Dermatol Res Pract. 2020; 2020: 9360476. doi: 10.1155/2020/9360476.

55. Andina D, Noguera-Morel L, Bascuas-Arribas M, Gaitero-Tristán J, Alonso-Cadenas JA, Escalada-Pellitero $S$ et al. Chilblains in children in the setting of COVID-19 pandemic. Pediatr Dermatol. 2020; 37 (3): 406-411. doi: 10.1111/pde.14215.

56. Locatelli AG, Robustelli Test E, Vezzoli P, Carugno A, Moggio E, Consonni $L$ et al. Histologic features of long-lasting chilblain-like lesions in a paediatric COVID-19 patient. J Eur Acad Dermatol Venereol. 2020; 34 (8): e365-e368. doi: 10.1111/jdv.16617.

57. Freeman EE, McMahon DE, Lipoff JB, Rosenbach M, Kovarik C, Takeshita J et al. Pernio-like skin lesions associated with COVID-19: A case series of 318 patients from 8 countries. J Am Acad Dermatol. 2020; 83 (2): 486-492. doi: 10.1016/j.jaad.2020.05.109.

58. Ramondetta A, Panzone M, Dapavo P, Ortoncelli M, Giura MT, Licciardello $M$ et al. Chilblain acral lesions in the COVID-19 era. Are they marker of infection in asymptomatic patients? J Eur Acad Dermatol Venereol. 2020; 34 (9): e440-e441. doi: 10.1111/ jdv.16636.

59. Kanitakis J, Lesort C, Danset M, Jullien D. Chilblain-like acral lesions during the COVID-19 pandemic ("COVID toes"): histologic, immunofluorescence, and immunohistochemical study of 17 cases. J Am Acad Dermatol. 2020; 83 (3): 870-875. doi: 10.1016/j. jaad.2020.05.145.

60. Herman A, Peeters C, Verroken A, Tromme I, Tennstedt D, Marot L et al. Evaluation of chilblains as a manifestation of the COVID-19 pandemic. JAMA Dermatol. 2020; 156 (9): 998-1003. doi: 10.1001/ jamadermatol.2020.2368.

Conflicto de intereses: Sin conflicto de intereses. 